\title{
AN OPTIMIZATION APPROACH FOR DISASTER RELIEF NETWORK DESIGN UNDER UNCERTAINTY AND DISRUPTION WITH SUSTAINABILITY CONSIDERATIONS
}

\author{
ZAHRA DESI-NEZHAD ${ }^{1}$, \\ Fatemeh Sabouhi ${ }^{2, *(1)}$ and Mohammad Hossein Dehghani Sadrabadi ${ }^{3}$ (0)
}

\begin{abstract}
Human-made, natural, and unexpected disasters always cause human and financial losses to communities. Disaster management is a framework with proven performance to reduce the damage caused by disaster and supply chain disruptions. Transferring the injured people from affected areas to hospitals at the minimum possible time is a crucial goal in times of disaster. This paper develops a two-stage stochastic programming model to transport the injured people from affected areas to hospitals in the incidence of multiple disruptions at transportation links and facilities under uncertainties. Herein, economic, social, and environmental aspects of sustainability are considered, while simultaneous disruptions are managed to minimize the adverse impacts of the disasters. We aim to determine optimal locations to establish transfer points and flows between the relief network nodes with sustainability considerations. Ultimately, a case study in District 12 of Tehran, Iran is conducted to ensure the proposed model's validity and performance. Various sensitivity analyses are also implemented to ensure the model's effectiveness. The results indicate that disruptions in facilities and transportation links lead to increased relief time, hence has the most significant negative impact on relief operations.
\end{abstract}

Mathematics Subject Classification. 90B06.

Received September 24, 2021. Accepted February 5, 2022.

\section{INTRODUCTION}

Human-made, natural, and unpredictable disasters always cause financial and human losses. The supply chain, as a large and broad part of disaster management, is tasked with providing and distributing necessary supplies (food, water, medicine, and shelter), the evacuation of healthy people from the disaster area, relief, rescue, temporary treatment, and temporary resettlement of the survivors, and activities of reconstruction $[11,12,37]$. A main goal is to transport wounded people from affected areas (AAs) to hospitals at the lowest possible time. Reducing relief and transportation time in disaster incidences is of vital importance and can be achieved using transfer points (TPs). Therefore, the TPs must be wisely located to transport the injured people at the minimum time and facilitate the relief operations. Due to the lack of resources, relief products, and

Keywords. Disruption, Disaster, Transfer Point, Stochastic Programming, Sustainability.

1 Department of Industrial Engineering, K. N. Toosi University of Technology, Tehran, Iran.

2 School of Industrial Engineering, College of Engineering, University of Tehran, Tehran, Iran.

3 Department of Industrial Engineering, Iran University of Science \& Technology, Tehran, Iran.

*Corresponding author: fatemehsabouhi@guest.ut.ac.ir

(c) The authors. Published by EDP Sciences, ROADEF, SMAI 2022 
transportation vehicles, a practical model should be extended and provided for the efficiency and effectiveness of the response operations by the relief chain in the occurrence of disasters [22,37].

Occasionally, natural disasters destroy buildings and block roads. The intensity of the destructions depends on the intensity of the natural disaster and the region's fabric. These disorders may cause a lack of relief or an increase in the transportation time of the injured from the AA. Also, regarding parameters with inherent uncertainty such as demand, supply, and unit cost in the first stage of response to natural disaster are of significant importance in relief supply chain management $[6,10,38]$. Uncertain parameters can lead to a reduction in the quality of relief received by the injured. Therefore, it is vital to consider disruption risks and uncertainties in optimization models in the disaster response phase.

On the other hand, environmental, social, and economic consequences of natural disasters have grown exponentially in recent decades. For instance, the economic costs of natural disasters have increased 14 times between 1960 and $2001[23,30,36,40]$. Although it is pretty challenging to accurately estimate the extent of damage a disaster can cause to humans' and societal trust, it is nonetheless crucial. Therefore, taking economic, social, and environmental aspects into account is necessary to minimize disaster's adverse impacts. Fair and equitable distribution of relief items including water, food, and clothing, as well as providing temporary residence facilities for the affected population and medical services for the injured are regarded as part of the social aspect of sustainability in a humanitarian supply chain $[2,14]$. Adopting an efficient procedure to conduct the post-disaster relief operation represents the economic aspect of sustainability. Moreover, making efforts to minimize the impact of the disaster on the environment ensures the environmental aspect of sustainability $[26,29,39,46,47]$. Although sustainability - especially from an environmental standpoint - is an important consideration when designing commercial supply chains and has always been addressed in the pertinent literature, considering sustainability in humanitarian supply chain network design is a relatively novel and hot research trend in relevant studies. Accordingly, sustainable development is a crucial component of humanitarian supply chains, and there is a perceptible need for optimization approaches that enables the integration of environmental, economic, and social considerations into the humanitarian supply chain network. Therefore, this study addresses a relief chain network design in the incidence of multiple disruptions in facilities and transportation links under uncertainty. For this purpose, we develop a stochastic model to transfer the injured from AAs to hospitals. The proposed model's decisions include locating TPs and determining the amount of flow between the nodes of the relief network with sustainability considerations. The suggested model considers economic and environmental components of sustainability via budget and pollution emissions constraints. Furthermore, social sustainability is implied by minimizing the total transportation time of the injured and the limitation of maximum relief time to each affected zone.

The content of this research is organized as follows: Section 2 reviews studies on relief chain network design under disruption and uncertainty. Sections 3 and 4 include problem description and model formulation, respectively. The conducted case study is explained, and the results are provided in Sections 5-7. Ultimately, conclusions and managerial results are discussed in Section 8.

\section{LiterATURE REVIEW}

Due to the importance of relief chain and TPs in the disaster incidence, numerous researches are being published, and different models are proposed to locate relief facilities such as TPs to speed up the relief process. It is crucial to carry out rescue operations as soon as possible, as transporting survivors to shelters and the injured to hospitals at the minimum possible time would significantly reduce the severity of the impacts. Note that the wounded have to be transported as soon as possible in the post-disaster phase. However, it is sometimes difficult to land the helicopters due to geographical roughness in the AAs. Accordingly, TPs are located between the AAs and hospitals and are used to reduce relevant damage and facilitate relief operations in natural and human-made disasters. Vehicles used between different nodes need to transport the injured people at an increasing rate to save time as much as possible [3]. Therefore, optimally locating shelters and TPs is vital for disaster management. 
For instance, Ghaderi and Momeni [17] proposed a multi-period maximal coverage model for locating ground and air emergency stations considering the inaccessibility of ambulances in light of the notion of backup coverage for providing services to the wounded and transporting them to treatment centers. Tzeng et al. [45] proposed a relief model to determine the absolute conditions of TPs in the distribution of goods. The objective functions include maximizing service satisfaction among the affected regions and minimizing the total cost and relief time. Two models were analyzed by Furuta and Tanaka [15] to minimax and minimize service times for locating TPs and helicopter stations in certain conditions, providing rapid and efficient relief services. Shahriari et al. [42] developed a bi-objective mathematical model that employed the compromise programming method to locate ground and air ambulance base and helipad locations under uncertainty. The main objectives of this model are the minimization of travel time and the maximization of level of service. Mansoori et al. [27] proposed a humanitarian relief network design problem with evacuation process under uncertainty and disruption caused by the earthquake. They aimed to minimize the unfulfilled demand for relief commodities, the total number of injured not transported to hospitals, remaining in the AA. Hassani and Mokhtari [19] designed a network for distributing relief commodities under operational risks. The objective functions include maximizing network population coverage and minimizing total costs and risks of the network. Akbarpour et al. [2] proposed a relief model for distribution of pharmaceutical items in AAs under uncertainty. They aimed to optimize coverage of AAs, pharmaceutical item's storage time, and mobility of the facilities.

The majority of information received in natural and human-made disasters has inherent uncertainties that can substantially influence the performance of relief operations; hence, the risk of rescue operations may increase sharply compared to deterministic environments [34]. Uncertainty is generally classified into random and epistemic categories. The random uncertainty arises from the random nature of the parameters. Stochastic programming approaches are usually used to tackle this type of uncertainty whenever statistical distribution is available for the random parameters $[28,32]$. Also, stochastic programming is employed in situations with a particular repetitive operation. Many modeling efforts on post-disaster relief operations use stochastic programming approaches to cope with uncertainty [16,44]. For instance, we can refer to models developed by Salmerón and Apte [41], Rawls and Turnquist [35], Bozorgi-Amiri et al. [6], Sheu and Pan [43], and Wang et al. [48].

Research on sustainable humanitarian supply chains is often qualitative $[4,13,18,24]$. Therefore, a limited number of studies proposed quantitative approaches and developed mathematical models $[1,6-9,20,21,25,31,33]$. However, the most relevant studies do not sufficiently consider all aspects of sustainability under disruptions in relief operations. Accordingly, there is a research gap in incorporating all three aspects in humanitarian supply chain network design. For instance, Cao et al. [8] considered the total carbon emitted throughout the relief operations and the required time to distribute relief items as the environmental and social aspects of sustainability, respectively. Wei et al. [49] considered the pollutions emitted by vehicles that transport relief items as the environmental aspect, while from a social point of view, their model is similar to Cao et al. [8]. Finally, Boostani et al. [5] considered three factors as the aspects of sustainability in the humanitarian supply chain: minimizing total supply chain costs, maximizing the victims' satisfaction, maximizing the equity in the distribution of relief items, and minimizing the total environmental impacts associated with packaging and transporting relief items.

Research gaps are also identified by reviewing studies on robust and resilient relief network design. Researches reveal that most of the parameters associated with relief network design in natural and human-made disaster situations must be considered under uncertainty and disruption incidence. Multiple disruptions in facilities and transportation links between them are not adequately considered in relevant studies. The two-stage stochastic programming (TSSP) method is typically employed to consider the conditions resulting from the occurrence of each disruption mode under uncertainty; However, a robust scenario-based approach with the ability to exert the simultaneous impacts of perturbations and disruptions on the deterministic model is required while maintaining robustness at a desirable level. Also, due to the increasing importance of sustainable development, it is necessary to incorporate sustainability's social, economic, and environmental pillars in rescue operations planning.

Accordingly, this study applies a mixed-integer linear programming model for evacuating injured people from AAs to hospitals in times of disaster. The model aims to determine the location of TPs and the flow of injured 
people amongst network components under sustainability considerations and multiple disruptions in facilities (i.e. TPs and hospitals) as well as transportation links. Budget constraint, environmental impact limitation, and the objective function of the total relief time to the disaster points represent economic, environmental, and social sustainability, respectively. Also, AAs' demand is considered to be inherently uncertain, hence, the TSSP approach is employed to deal with it. Finally, a case study in District 12 of Tehran, Iran is applied to the proposed formulation for ensuring model applicability and validation. Sensitivity analyses are also implemented to verify the model.

\section{Problem Definition}

Transportation of the injured people from AAs at a minimum possible time is the main priority during disasters such as earthquakes, floods, and fires. Note that the number of the injured in each region may be variable depending on the fabric of the affected region, which needs to be recognized as well. Besides, the severity of disaster determines the extent of the damage they cause; Therefore, a disaster with high severity causes disruptions such as the destruction of facilities and transportation links between them.

According to Figure 1, The AAs are considered as demand points needing relief operations for transporting the injured either directly by ambulance or indirectly by helicopter to speed up the rescue process. In other words, the injured are taken using an ambulance when hospitals are not very far from the AA, hence the injury is not further aggravated. Otherwise, if the distance is too far or the nearest hospitals have reached their maximum level of service, the injured are transported using helicopters via TPs. Transferring the injured by TP involves the following steps; At the request of the rescue team, the helicopter first flies from the central station to the nearest TP, then the injured are transported to the hospital. Note that the number of injured transferred directly depends on the predefined capacity of the helicopters and hospitals.

This study develops an optimization model to locate TPs with sustainability considerations under multiple disruptions in transportation links and facilities. The proposed model considers economic and environmental sustainability aspects in the form of budget, and environmental emissions constraints. Moreover, the objective function of minimizing the total transportation time of the injured and the constraint of maximum relief time to each AA implies the social dimension of sustainability. Also, some parameters such as the number of the injured

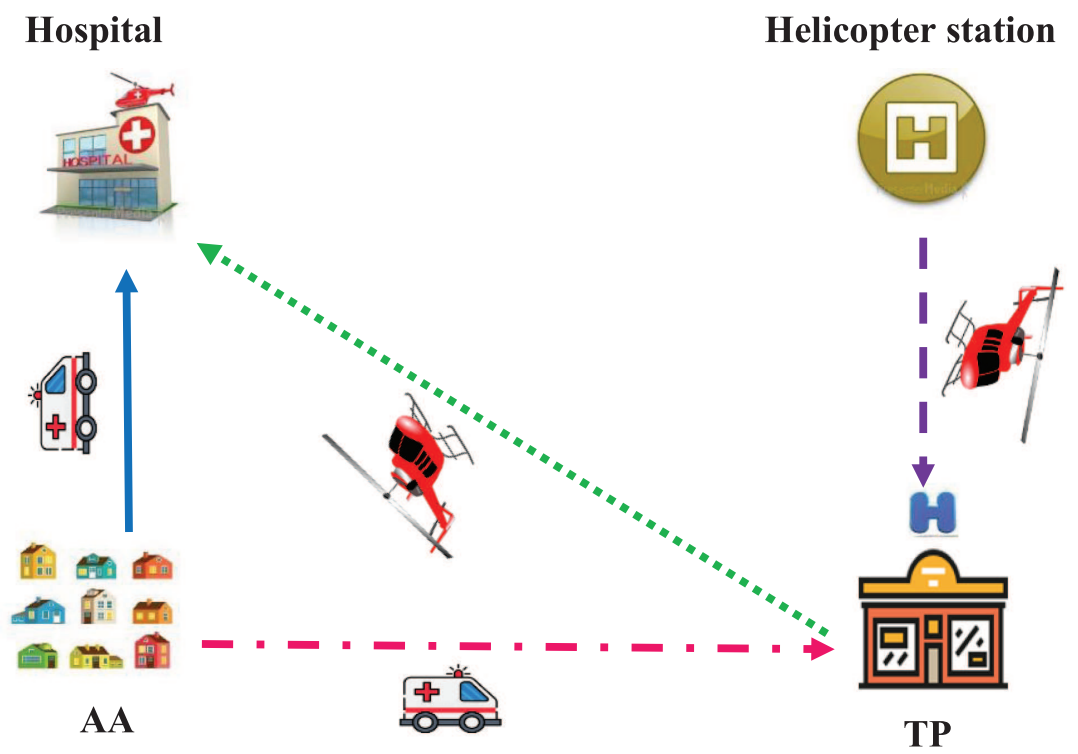

Figure 1. Configuration of considered relief chain in the post-disaster phase. 
in AAs, disrupted links between network nodes and lost capacity of the disturbed facilities are considered under uncertainty that is tackled employing TSSP method. Note that AAs and helicopter stations, hospitals, and TPs are capacitated and respectively considered as departure, destination, and intermediate points in the proposed model.

\section{Model FORMUlation}

TSSP is employed to formulate the problem under uncertainty so that the decision variables are considered pre-event (first stage or scenario independent) and post-event (second stage or scenario dependent). Pre-event decisions include establishing TPs, and post-event decisions involve determining the number of injured transported between AAs and TPs, AAs and hospitals, and TPs and hospitals in the proposed model. Parameters and variables associated with the proposed two-stage linear model are explained below.

Sets

$S \quad$ Set of scenarios, indexed as $s \in S$

$J \quad$ Set of TPs, indexed as $j \in J$

$H \quad$ Set of hospitals, indexed as $h \in H$

$K \quad$ Set of helicopter stations, indexed as $k \in K$

$I \quad$ Set of AAs, indexed as $i \in I$

\section{Parameters}

$d_{i s} \quad$ The population of AA $i \in I$ must be transferred under scenario $s \in S$

$t_{i j} \quad$ Transfer time from AA $i \in I$ to TP $j \in J$

$t_{i h}^{\prime} \quad$ Transfer time from AA $i \in I$ to hospital $h \in H$

$t_{j h}^{\prime \prime} \quad$ Transfer time from TP $j \in J$ to hospital $h \in H$

$t_{k j}^{\prime \prime \prime} \quad$ Transfer time from helicopter station $k \in K$ to TP $j \in J$

$n_{K} \quad$ Velocity coefficient of helicopter employed to transfer wounded people

$m_{A} \quad$ Velocity coefficient of ambulance employed to transfer wounded people

$e \quad \max \left\{m_{A} t_{i j} \cdot n_{k} t_{k j}^{\prime \prime \prime}\right\} \quad \forall k \in K \cdot \forall i \in I \cdot \forall j \in J$

$g \quad$ Number of TPs must be established

$B_{h} \quad$ Maximum capacity of hospital $h \in H$

$A_{j} \quad$ Maximum capacity of TP $j \in J$

$p_{s} \quad$ Possibility of occurrence of scenario $s \in S$

$f_{i j s} 1$ if transportation link between demand point $i \in I$ and $\operatorname{TP} j \in J$ is disrupted under scenario $s \in S ; 0$, otherwise

$w_{\text {ihs }} 1$ if transportation link between demand point $i \in I$ and hospital $h \in H$ is disrupted under scenario $s \in S$; 0 , otherwise

$r_{j h s} 1$ if transportation link between $\operatorname{TP} j \in J$ and hospital $h \in H$ is disrupted under scenario $s \in S ; 0$, otherwise

$l_{j s} \quad$ Percentage lost capacity of TP $j \in J$ under scenario $s \in S$

$v_{h s} \quad$ Percentage lost capacity of hospital $h \in H$ under scenario $s \in S$

$T_{\max }$ Maximum relief time to each AA

$c_{i j} \quad$ Unit transmission cost from AA $i \in I$ to TP $j \in J$

$c_{i h}^{\prime} \quad$ Unit transmission cost from AA $i \in I$ to hospital $h \in H$

$c_{j h}^{\prime \prime} \quad$ Unit transmission cost from TP $j \in J$ to hospital $h \in H$

$c_{k j}^{\prime \prime \prime} \quad$ Unit transmission cost from helicopter station $k \in K$ to TP $j \in J$

$o_{j} \quad$ Cost of establishing a TP at location $j \in J$

$C_{\max }$ Maximum available budget

$q_{i j} \quad$ Unit negative environmental impact of transportation from AA $i \in I$ to $\operatorname{TP} j \in J$ 
$q_{i h}^{\prime} \quad$ Unit negative environmental impact of transportation from AA $i \in I$ to hospital $h \in H$

$q_{j h}^{\prime \prime} \quad$ Unit negative environmental impact of transportation from TP $j \in J$ to hospital $h \in H$

$q_{k j}^{\prime \prime \prime} \quad$ Unit negative environmental impact of transportation from helicopter station $k \in K$ to TP $j \in J$

$Q_{\max }$ Maximum acceptable rate for negative environmental impacts of the network

\section{Decision variables}

$U_{j} \quad 1$ if a TP is established at location $j \in J ; 0$, otherwise

$X_{i j s} \quad$ Number of the injured transported from AA $i \in I$ to TP $j \in J$ under scenario $s \in S$.

$Y_{i h s} \quad$ Number of the injured transported from AA $i \in I$ to hospital $h \in H$ under scenario $s \in S$.

$Z_{j h s}$ Number of the injured transported from TP $j \in J$ to hospital $h \in H$ under scenario $s \in S$.

\subsection{Mathematical model}

The objective function and constraints are provided based on TSSP as follows.

$$
\begin{array}{ll}
\operatorname{Min}_{s \in S} P_{s}\left(m_{A} \sum_{i \in I} \sum_{h \in H} t_{i h}^{\prime} Y_{i h s}+\sum_{i \in I} \sum_{j \in J} e X_{i j s}+n_{K} \sum_{j \in J} \sum_{h \in H} t_{j h}^{\prime \prime} Z_{j h s}\right) & \\
\text { s.t. } & \\
\sum_{i \in I} X_{i j s}=\sum_{h \in H} Z_{j h s} & \forall j \in J \cdot \forall s \in S \\
\sum_{j \in J} X_{i j s}+\sum_{h \in H} Y_{i h s}=d_{i s} & \forall i \in I \cdot \forall s \in S \\
\sum_{i \in I} X_{i j s} \leq\left(1-l_{j s}\right) A_{j} U_{j} & \forall j \in J \cdot \forall s \in S \\
\sum_{i \in I} Y_{i h s}+\sum_{j \in J} Z_{j h s} \leq\left(1-v_{h s}\right) B_{h} & \forall h \in H \cdot \forall s \in S \\
\sum_{j \in J} U_{j} \leq g & \\
X_{i j s} \leq\left(1-f_{i j s}\right) A_{j} & \\
Y_{i h s} \leq\left(1-w_{i h s}\right) B_{h} & \forall i \in I \cdot \forall j \in J \cdot \forall s \in S \\
Z_{j h s} \leq\left(1-r_{j h s}\right) B_{h} & \forall i \in I \cdot \forall h \in H \cdot \forall s \in S \\
m_{A} \sum_{h \in H} t_{i h}^{\prime} Y_{i h s}+\sum_{j \in J} e X_{i j s}+n_{K} \sum_{j \in J} \sum_{h \in H} t_{j h}^{\prime \prime} Z_{j h s} \leq T_{\max } & \forall j \in J \cdot \forall h \in H \cdot \forall s \in S \\
\sum_{s \in S} P_{s}\left(\sum_{i \in I} \sum_{h \in H} c_{i h}^{\prime} Y_{i h s}+\sum_{k \in K} \sum_{i \in I} \sum_{j \in J}\left(c_{i j}+c_{k j}^{\prime \prime \prime}\right) X_{i j s}+\sum_{j \in J} \sum_{h \in H} c_{j h}^{\prime \prime} Z_{j h s}\right)+\sum_{j \in J} o_{j} U_{j} \leq C_{\max } & \forall i \in I \cdot \forall s \in S \\
\sum_{s \in S} P_{s}\left(\sum_{i \in I} \sum_{h \in H} q_{i h}^{\prime} Y_{i h s}+\sum_{k \in K} \sum_{i \in I} \sum_{j \in J}\left(q_{i j}+q_{k j}^{\prime \prime \prime}\right) X_{i j s}+\sum_{j \in J} \sum_{h \in H} q_{j h}^{\prime \prime} Z_{j h s}\right) \leq Q_{\max } & \forall i \in I \cdot \forall h \in H \cdot \forall s \in s \\
U_{j} \in\{0.1\} & \forall j \in J \cdot \forall h \in H \cdot \forall s \in s . \\
X_{i j s} \geq 0 & \\
Y_{i h s} \geq 0 & \\
Z_{j h s} \geq 0 &
\end{array}
$$


TABLE 1. Estimated demand of AAs in district 12 of Tehran Municipality.

\begin{tabular}{lll}
\hline \hline Zones & AAs & $d_{i s}=\left(d_{i 1}, d_{i 2}, d_{i 3}\right)$ \\
\hline 1 & Sadi Street & $(2200,2600,3000)$ \\
2 & Naser Khosro Street & $(1500,2000,2400)$ \\
3 & Mehdi Alley & $(2400,2800,3000)$ \\
4 & Harandi Stadium & $(4700,5000,5400)$ \\
5 & Khorasan Square & $(3700,4000,4222)$ \\
6 & Mojahedin Eslam Street & $(6000,6300,6640)$ \\
\hline
\end{tabular}

TABLE 2. The occurrence probability of the scenarios.

\begin{tabular}{llll}
\hline \hline Probable scenarios & Optimistic & Most likely & Pessimistic \\
\hline$p_{s}$ & 0.35 & 0.5 & 0.15 \\
\hline
\end{tabular}

The objective function (4.1) represents the total transportation time. Constraint (4.2) ensures the flow balance equation for TPs. Constraint (4.3) illustrates the total number of injured transported to hospitals and TPs need to be equal to total population needing transportation in each AA. Constraints (4.4) and (4.5) express the maximum capacity of TPs and hospitals, respectively. Constraint (4.6) guarantees that the number of TPs does not exceed the maximum allowable number of TPs. Constraints (4.7)-(4.9) guarantee that the injured are transported via available links. Constraints (4.10)-(4.12) ensure the sustainability considerations for relief operations. Maximum relief time for each AA is considered in constraint (4.10). Constraints (4.11) shows that the total cost must not exceed the maximum available budget. Constraint (4.12) limits the total negative environmental impacts of transportation. Constraints (4.13)-(4.16) represent the domain of binary and continuous variables.

\section{CASE Study}

The case study is conducted in Iran, particularly, district 12 of its capital city Tehran. District 12 is located in the historical center of Tehran. Tehran Grand Bazaar, numerous state institutions, ministries, and embassies are the district's most important attractions and buildings. According to Tehran's administrative divisions, the investigated district is divided into six zones, and the centers of these zones are considered as AAs in the relief network. Table 1 illustrates the estimation of the injured needing to be transported from each AA due to the context of each zone, the severity of the disaster that may take place, and other influential factors. Three independent scenarios, including optimistic, most likely, and pessimistic, are generated considering disaster severity, and the possibility of occurrence for each scenario is estimated, as shown in Table 2.

Table 3 shows that there are 18 hospitals as existing facilities and nine candidate locations for establishing TPs are considered in the case study. Note that the number of established TPs must not exceed a maximum of seven. The capacity of a candidate TP for evacuating the injured is considered to be 2000; however, the capacities of hospitals are variable based on their difference in their equipment and facilities, that are outlined in Table 4. The proposed model addresses simultaneous disruptions in facilities and transportation links; therefore, due to the distinctive fabric of the AAs and severity of the disaster, some routes will not be exploitable for relief processes under particular disruption scenarios. The travel times between nodes are calculated based on their distance via the Google Map platform. Also, the speed coefficients of ambulances and helicopters relative to standard vehicles are 0.3 and 0.1 , respectively. 
TABLE 3. Considered facilities.

\begin{tabular}{ll}
\hline \hline Facility type & Specification \\
\hline Hospital & Sina, Naft, Dadgostari, Bank Melli Iran, Amir A'lam, Torfeh, Dr. Sapir, \\
& Seyyed Al Shohada, Razi, Ashrafi Isfahani, Akbar Abadi, Sevom-e- \\
& Shaban, Bazarganan, Shafa Yahyaian, Dr. Mo'eiri, Najmiyeh, Baharlu, \\
and Mahdiyeh & \\
TP & Heidarnia Stadium, Alavi High School. Moshki Street, Zoroufchian \\
& Alley, Khayyam Street disaster warehouse, Hagani park, Saeedi Sports \\
& Complex, School physical education Chamran, Farhangian Wedding \\
Helicopter station & venue, Tehran electric Sport Complex \\
\hline
\end{tabular}

TABLE 4. The capacity of hospitals.

\begin{tabular}{ll}
\hline \hline Hospitals & Capacity \\
\hline Dadgostari & 700 \\
Sina & 2100 \\
Naft & 1300 \\
Bank Melli Iran & 1800 \\
Amir A'lam & 1700 \\
Torfeh & 1000 \\
Dr. Sapir & 400 \\
Seyyed Al Shohada & 1300 \\
Razi & 2500 \\
Ashrafi Isfahani & 1800 \\
Akbar Abadi & 700 \\
Sevom-e-Shaban & 1800 \\
Bazarganan & 2000 \\
Shafa Yahyaian & 2000 \\
Dr. Mo'eiri & 700 \\
Najmiyeh & 2000 \\
Baharlu & 2000 \\
Mahdiyeh & 1800 \\
\hline
\end{tabular}

\section{Results}

The mathematical model was coded and solved using GAMS 24.1.2 and CPLEX solver on a laptop with specifications including Intel Core i7-8565U CPU, $1.80 \mathrm{GHz}$ to $1.99 \mathrm{GHz}$ with $8 \mathrm{~GB}$ of RAM. Results indicate the total travel time is equal to 28 min. Besides, Heidarnia Stadium, Alavi High School, Moshki Street, Zoroufchian Alley, Khayyam Street disaster warehouse, Hagani Park, Chamran School of physical education, and Farhangian Wedding venue are activated as TPs. The flow among nodes is determined under each disruption scenario, represented in Figures 2-4.

An overall observation implies that the use of the facilities (i.e. TPs and hospitals) is sharply increased under pessimistic scenario; The rationale behind this behavior is that the occurrence of the discussed scenario leads to the rescue chain facing the greatest number of the injured, and given that the network intends to perform rescue operations in minimum possible time, therefore, the use of facilities sharply increases. For instance, nearly $100 \%$ of the Sevom Shaban hospital's capacity was used under the pessimistic scenario, whereas that facility was not employed under the most likely and optimistic scenarios. Also, about 50\% of Haqani park TP's capacity, is used 

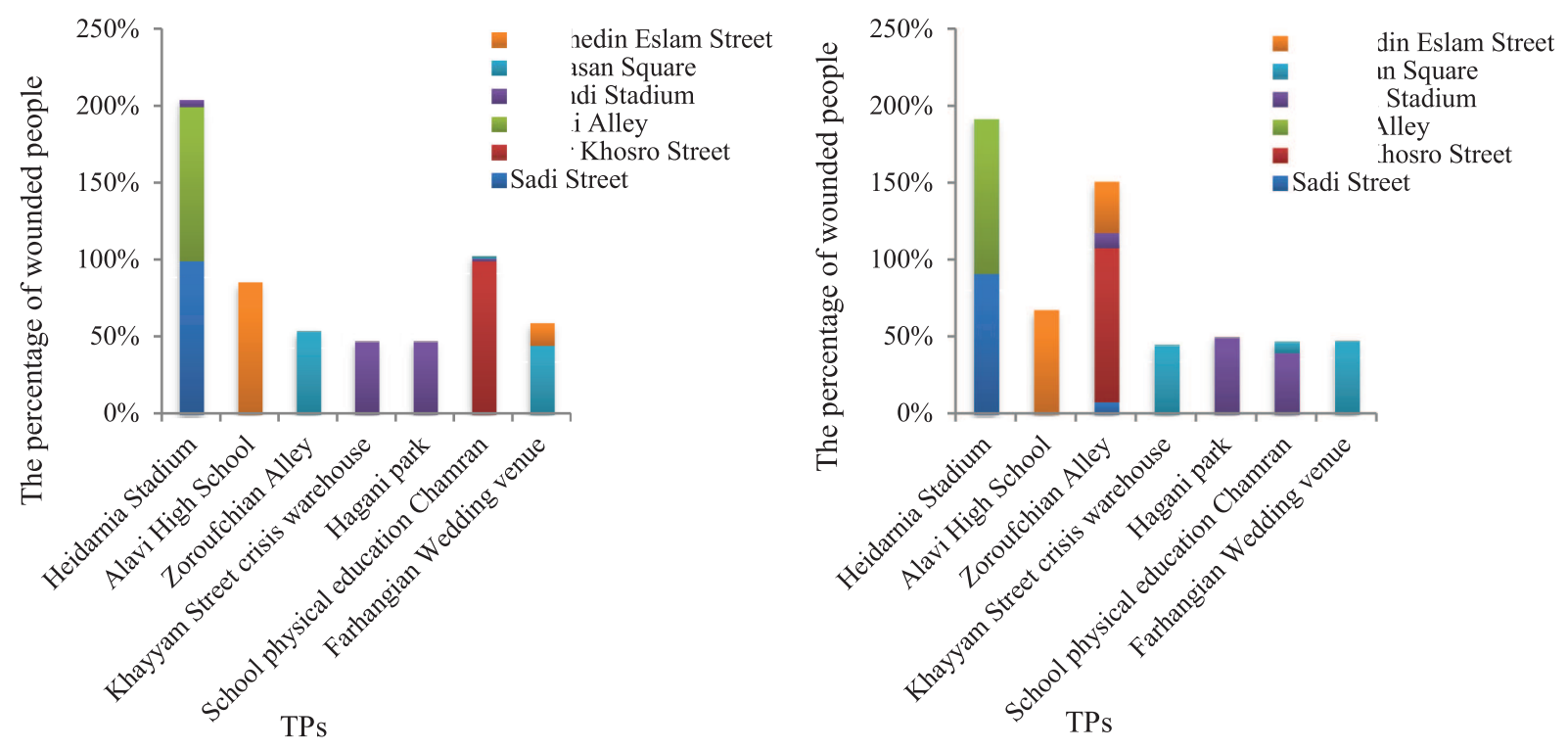

$\mathrm{a}$

b

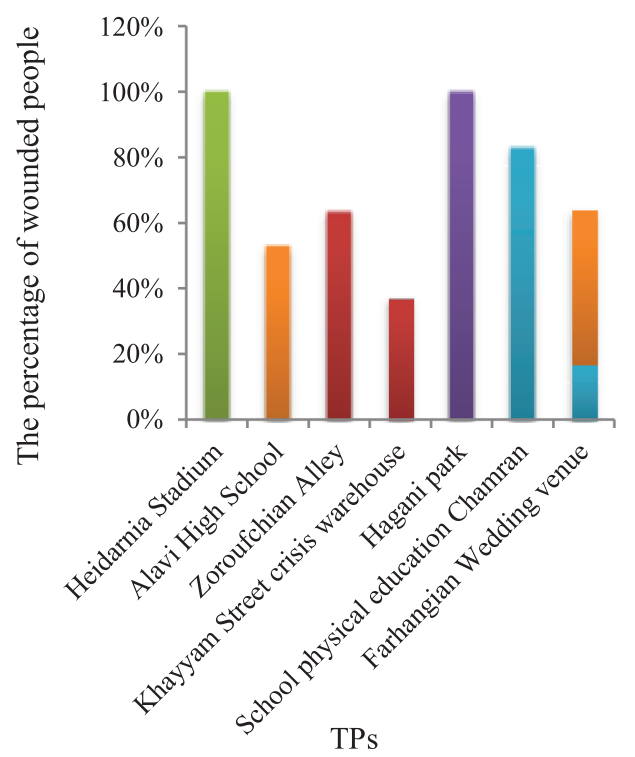

- Mojahedin Eslam Street

Khorasan Square

- Harandi Stadium

Mehdi Alley

- Naser Khosro Street

aSadi Street

$\mathrm{c}$

Figure 2. The flow between demand points and TPs under all scenarios. (a) Optimistic scenario. (b) Most likely scenario. (c) Pessimistic scenario. 


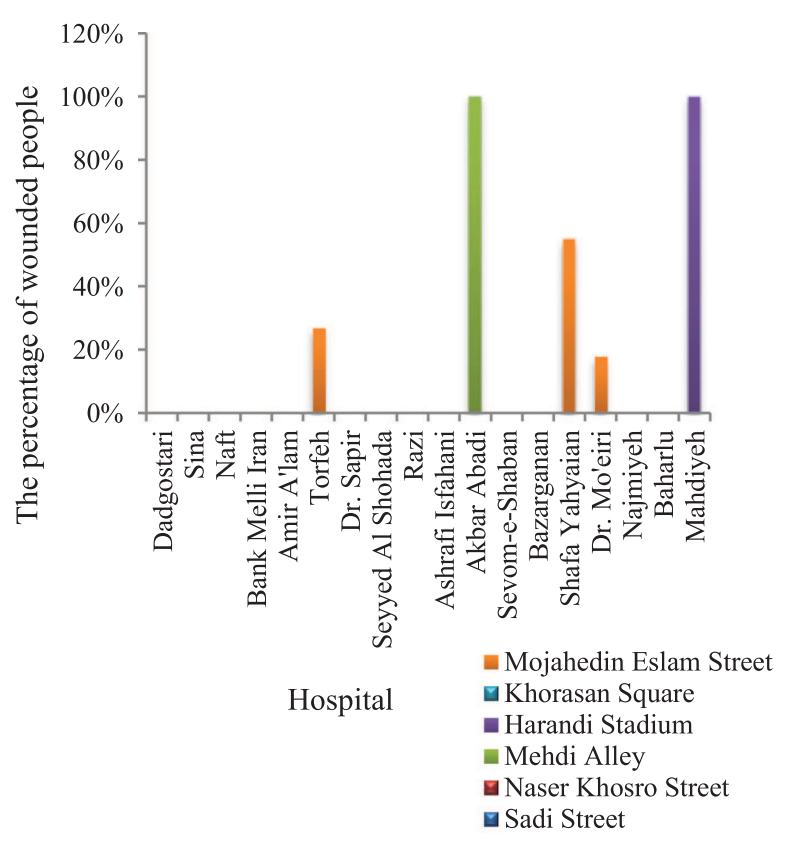

a

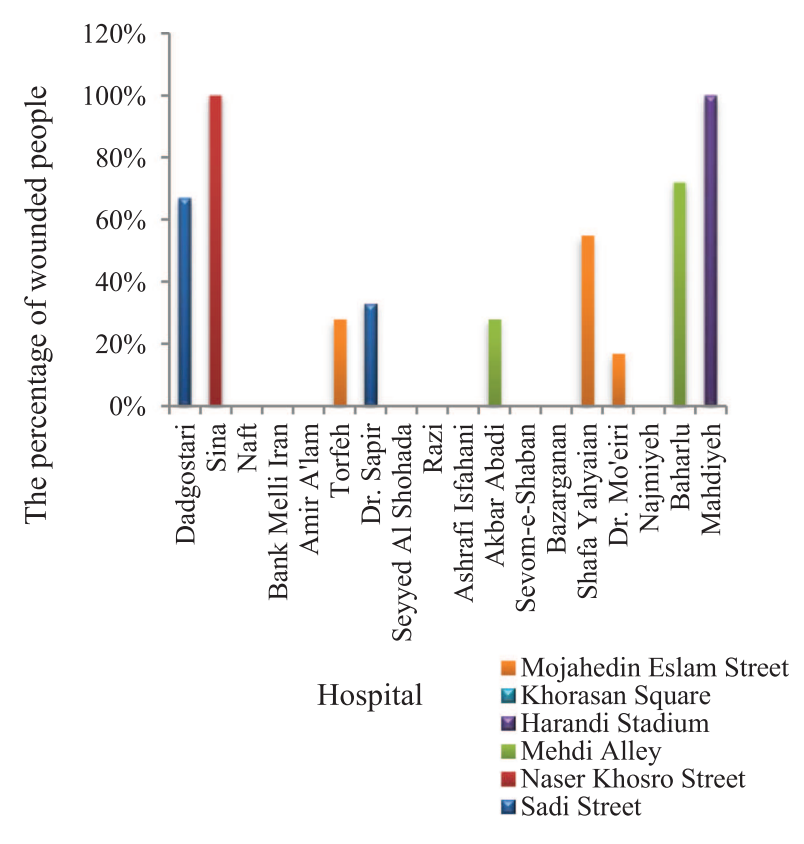

b

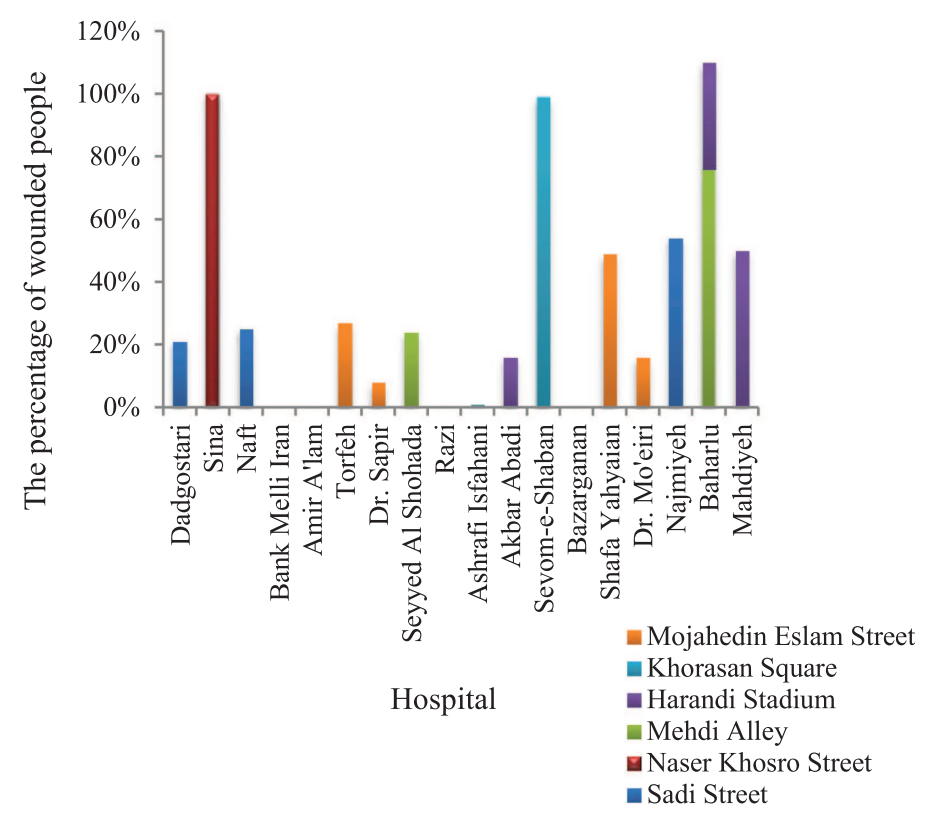

$\mathrm{c}$

Figure 3. The flow between demand points and hospitals under all scenarios. (a) Optimistic scenario. (b) Most likely scenario. (c) Pessimistic scenario. 


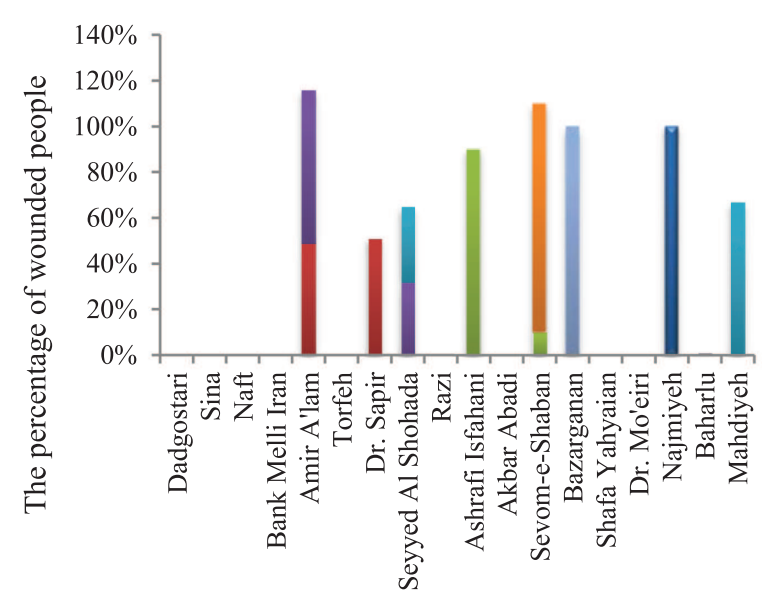

- Farhangian Wedding venue

w School physical education Chamran

- Hagani park

- Khayyam Street crisis warehouse

- Zoroufchian Alley

- Alavi High School

घ Heidarnia Stadium

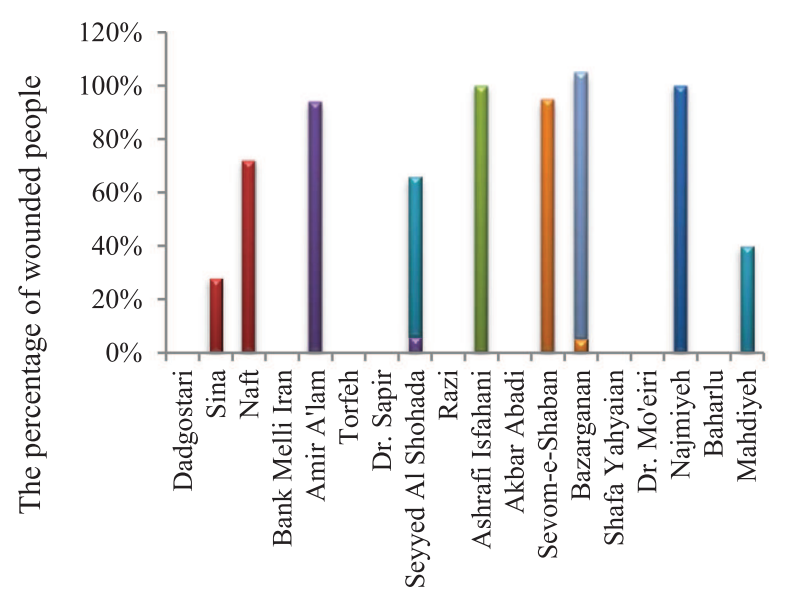

$\square$ Farhangian Wedding venue

Hospital

$\square$ School physical education Chamran

- Hagani park

@ Khayyam Street crisis warehouse

$\square$ Zoroufchian Alley

alavi High School

a Heidarnia Stadium

a

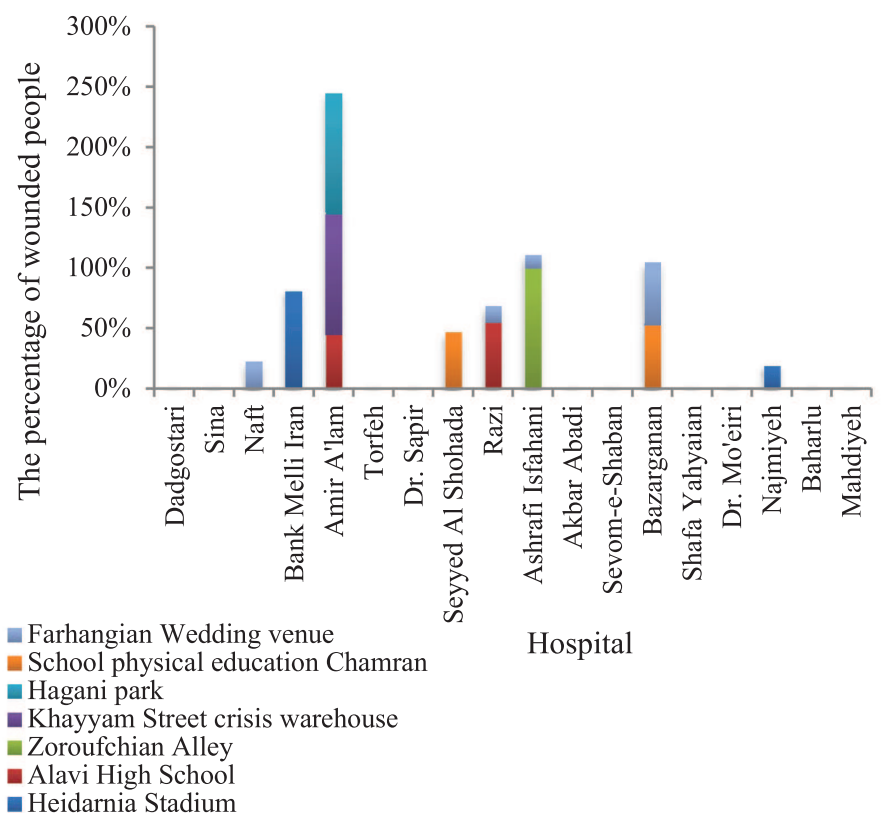

c

Figure 4. The flow between TPs and hospitals under all scenarios. (a) Optimistic scenario. (b) Most likely scenario. (c) Pessimistic scenario. 


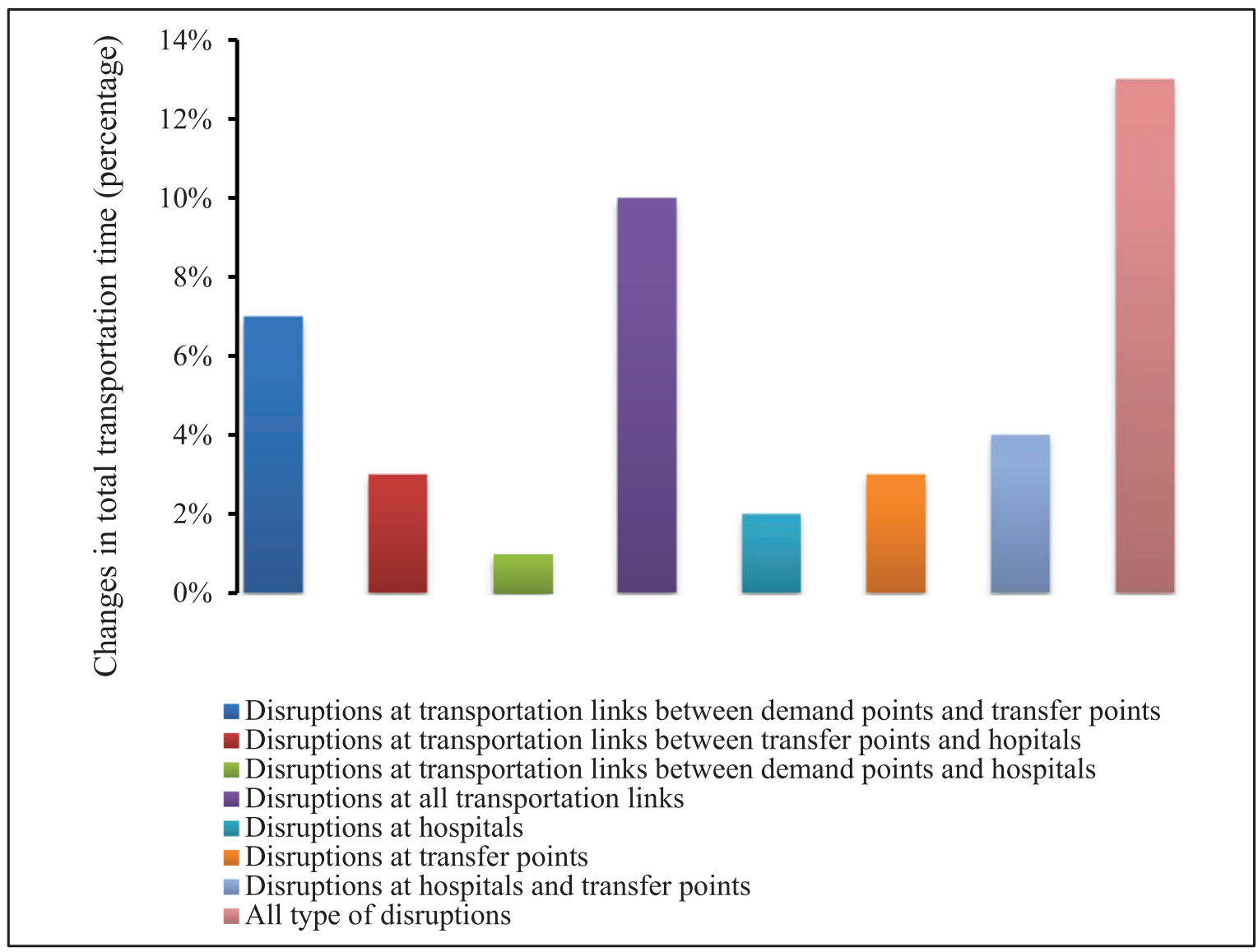

FiguRE 5. Impact of considering different disruptions on the total transportation time.

to transport the injured from the AAs under the optimistic and most likely scenarios, while the used capacity of the aforementioned facility is close to $100 \%$ under the pessimistic scenario. The Mahdieh and Amir A'lam hospitals that have the maximum capacity among existing hospitals, provide services to the injured with total capacity under all scenarios, so the used capacity of these two hospitals is completely scenario-independent. Similarly, Figure 2 indicates that the Heidarnia Stadium TP serves the injured from the AAs at total capacity under all scenarios; the rationale behind this behavior is that the mentioned TP has the shortest distance to two high-demand AAs Mehdi Alley and Sadi Street.

Disruptions can significantly affect the time it takes to rescue and transport the injured, so relief processes may face numerous problems. This study addresses partial disruptions in facilities, including TPs, hospitals, and complete disruptions in transportation links between different nodes. Figure 5 shows how the previously mentioned disruptions affect the total transportation or rescue time, indicating exciting and significant results. Note that the expected total transportation time changes are separately calculated under each disruption to evaluate the severity of the disturbances on the relief time. Results indicate a complete disruption in transportation links, particularly, the disrupted links between AAs and TPs, dramatically increases the transportation time. Also, when all possible disruptions are simultaneously considered, the relief time increases by about $13 \%$ compared to the situation without disturbance. Accordingly, results imply that considering complete disruptions in transportation links leads to a more significant increase in the total rescue and transportation time compared to partial disturbances in facilities. 


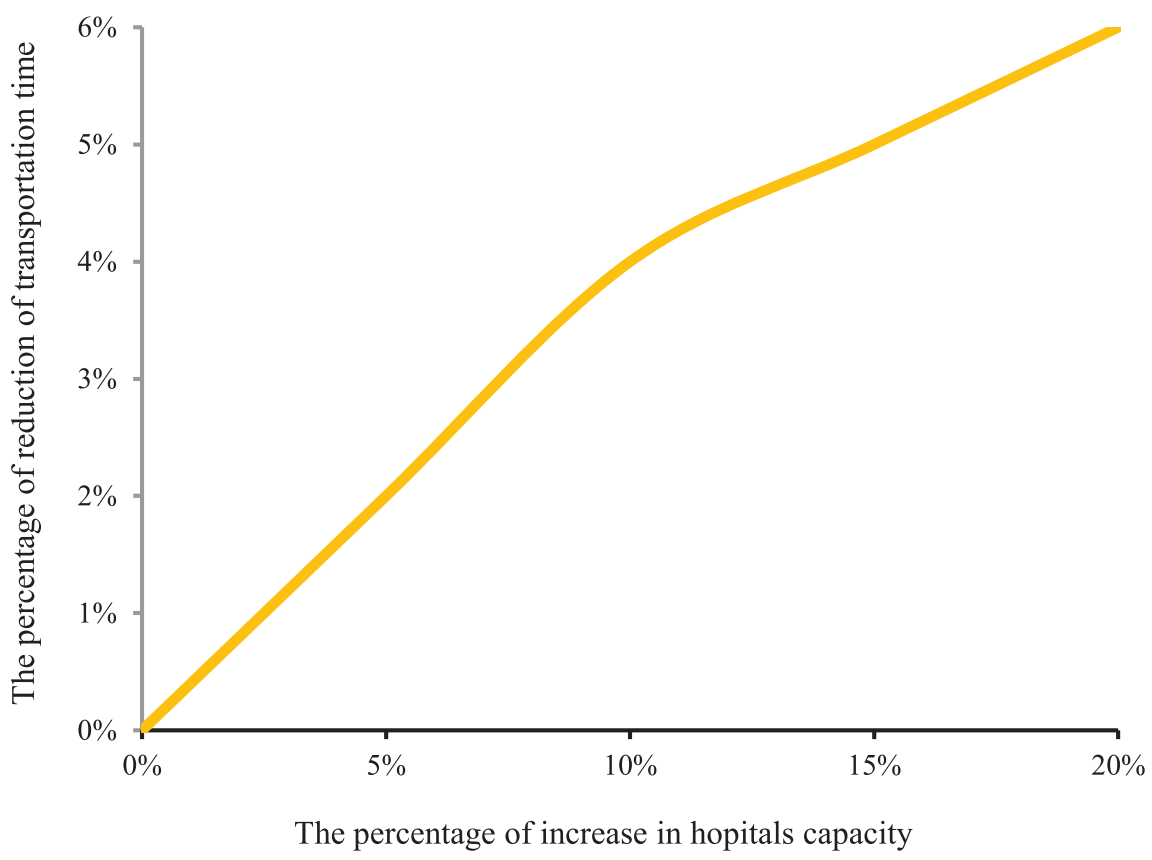

FIgURE 6. Impact of changing hospital capacity on the total transportation time.

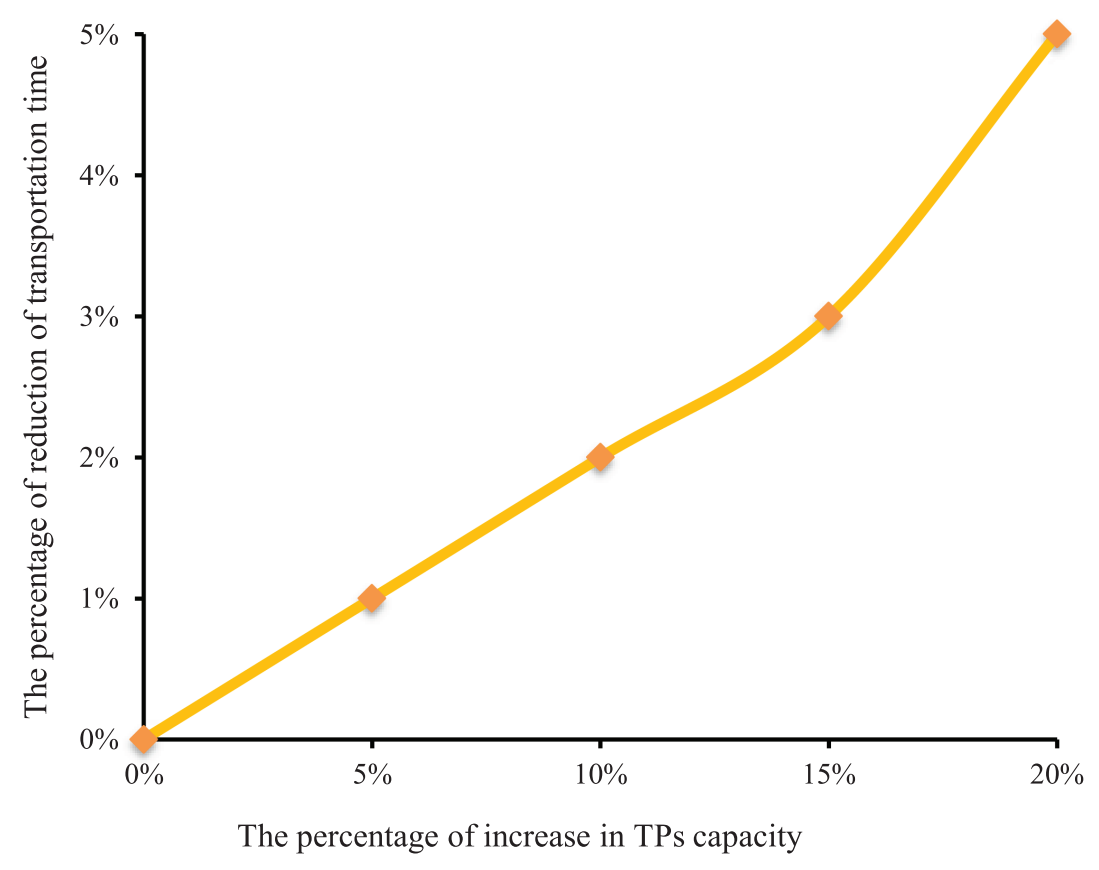

FIGURE 7. Impact of changing TP capacity on the total transportation time. 


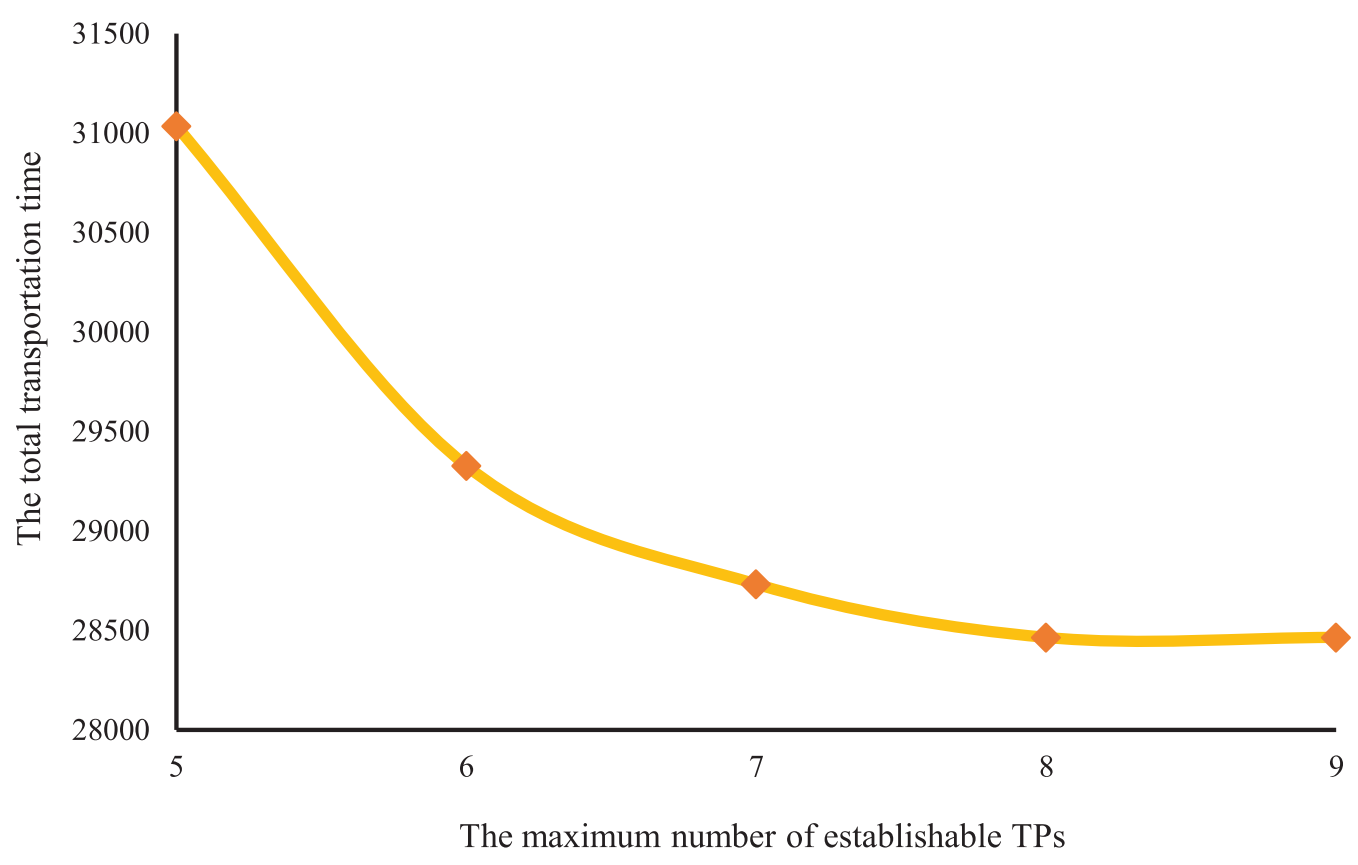

FIGURE 8. Impact of changing the maximum number of TPs can be established on the objective function.

The sensitivity analysis is implemented on the capacity of TPs and hospitals to ensure the verification and application of the proposed model. Figures 6 and 7, respectively imply that an increase in the capacity of hospitals and TPs leads to a remarkable reduction in the total transportation and relief time.

The impact of changing the maximum allowable number of TPs on the total relief operations' time is evaluated below. Figure 8 illustrates that increasing the parameter significantly decreases the total transportation time. The rationale behind this behavior is that some TPs may not be available under multiple disruptions in facilities and links connecting them. So, the more TPs are established, the more the injured can be transferred from the AAs to the hospitals via TPs. Accordingly, reducing the number of transfers by helicopters and ambulances leads to a remarkable decrease in the total transfer time.

Furthermore, the total transportation time is optimized separately under each scenario. Note that the optimistic scenario, in contrast with the pessimistic one, considers a situation in which the severity of disruption is less in terms of negative impacts. Figure 9 illustrates that an increment in disaster's severity remarkably increases the total transportation time. The logic behind this behavior is that facilities and transportation links are simultaneously disrupted in the relief network, and the more severe the disruption, the greater its harmful effects, which further reduces the available capacity of facilities and closes more transportation links. This, consequently, slows down the transfer of the injured. Thus, the total transportation time sharply increases by incrementing the disaster severity.

\section{Managerial insights}

Herein, the most important practical and managerial insights from the aforementioned numerical results are listed. Due to the inherent uncertainty caused by supervenient disasters, important parameters related to the relief process, such as the number of injured in AAs, cannot be accurately estimated, thus, the relief network management needs to adopt a robust approach for resilient planning in such situations. Initial observations indicate that disruption in links has the most negative impacts on relief times and endangers the survival of the 


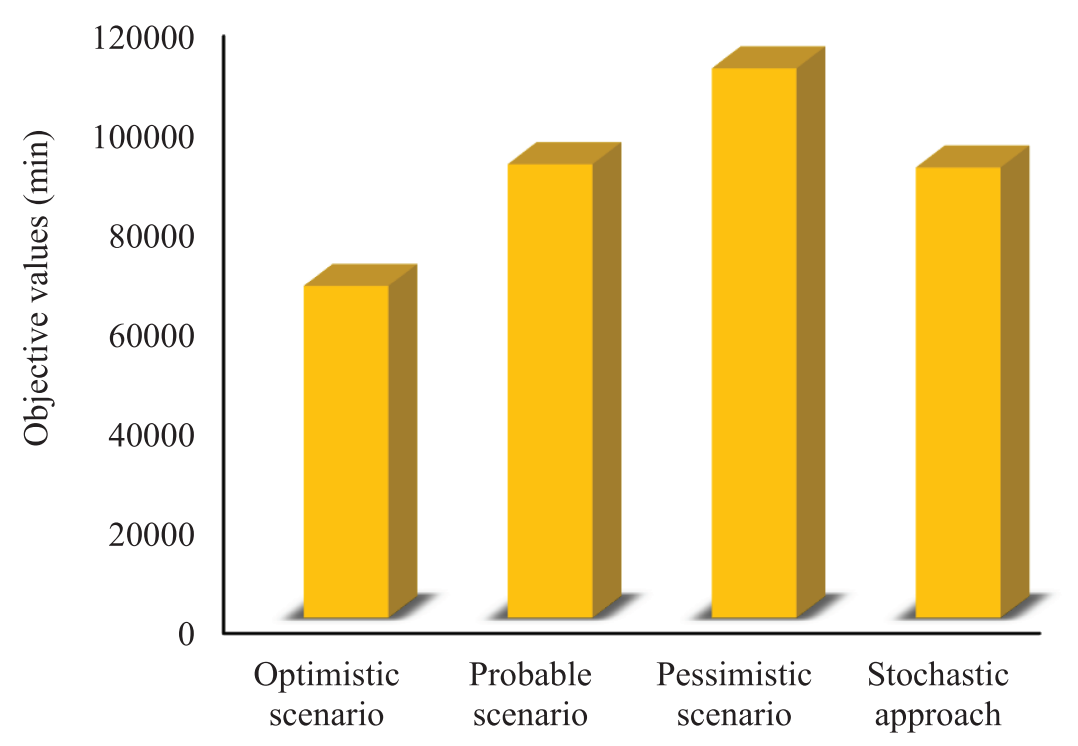

Figure 9. Total transportation time under each scenario.

injured, so fortifying relief infrastructures and considering backup transportation links can be perfectly helpful in disaster incidence. Due to the lack of available resources and time for relief operations in disaster situations, it is necessary to make appropriate investments to optimally increase the capacity of relief facilities in order to serve more injured people in a shorter time, while lowering costs.

\section{CONCLUSiOn}

The most important priority of disaster management decision-makers is to carry out rescue operations in the minimum possible time because relief time directly affects the severity of injuries and the death rate. One of these operations is to evacuate the injured from the AAs to the hospitals. In this regard, this study addresses a mixed-integer linear programming model for locating TPs under disruption and uncertainties considering sustainability considerations. Environmental pollution and budget constraints were considered as environmental and economic pillars of sustainability in the model. Also, the objective function of minimizing the total time required to transport the injured and the constraint of maximum relief time for each AA represent the social dimension of sustainability. Due to the negative impact of the disaster on relief chain management, it is assumed that the facilities, including TPs and hospitals, are partially disrupted, and the transportation links connecting different network nodes may be completely disturbed. Due to the lack of precise data on the hypothetical number of individuals injured, the share of the population of each AA that need to be transferred to hospitals is considered to be uncertain, and a TSSP approach is employed to deal with uncertainties. Moreover, the capacity constraint for TPs and hospitals is incorporated to further adapt the model to real-world situations. Finally, a case study of Iran, particularly, district 12 of Tehran province is conducted to ensure the practical application as well as validation of the proposed model and the results and various sensitivity analyses are reported.

The results indicate that disrupted facilities and transportation links lead to increased relief time, so disruption in links has the most significant negative impact on relief operations. Accordingly, decision-makers aim to use facilities with sufficient capacity to optimize available time and resources to provide the most effective rescue operations to all AAs in the minimum possible time. Therefore, sensitivity analysis was implemented on the capacity of hospitals and TPs, and the maximum number of TPs allowed. The impact of different scenarios, 
including pessimistic, most likely, and optimistic scenarios, on the evacuation and transportation of the injured people among components of the relief network is also evaluated. Results illustrate that those facilities with the highest capacity and minimum distance to AAs are employed to achieve the rescue network's minimum relief time.

Despite the intended contributions, the present research is not without limitations. This study can be contributed in several directions, such as incorporating the distribution network of relief commodities to the proposed model, considering shelters for covering and protecting healthy people, and considering fairness in relief operations. Also, adopting both reactive and proactive resilience strategies to manage disruptions and applying appropriate robust optimization approaches to cope with operational risks arising from the inherent uncertainty of parameters can further reinforce the contributions of this study.

Acknowledgements. The authors are grateful to esteemed editor and anonymous reviewers of this journal for their helpful comments and suggestions for improving the paper.

\section{REFERENCES}

[1] D. Adebanjo, P.-L. Teh and P.K. Ahmed, The impact of supply chain relationships and integration on innovative capabilities and manufacturing performance: the perspective of rapidly developing countries. Int. J. Prod. Res. 56 (2018) 1708-1721.

[2] M. Akbarpour, S.A. Torabi and A. Ghavamifar, Designing an integrated pharmaceutical relief chain network under demand uncertainty. Transp. Res. Part E: Logistics Transp. Rev. 136 (2020) 101867.

[3] O. Berman, Z. Drezner and G.O. Wesolowsky, The facility and transfer points location problem. Int. Trans. Oper. Res. 12 (2005) 387-402.

[4] A. Boostani, F. Jolai and A. Bozorgi-Amiri, Optimal location selection of temporary accommodation sites in Iran via a hybrid fuzzy multiple-criteria decision making approach. J. Urban Planning Dev. 144 (2018) 04018039.

[5] A. Boostani, F. Jolai and A. Bozorgi-Amiri, Designing a sustainable humanitarian relief logistics model in pre-and postdisaster management. Int. J. Sustainable Transp. 15 (2021) 604-620.

[6] A. Bozorgi-Amiri, M.S. Jabalameli and S.M. Al-e-Hashem, A multi-objective robust stochastic programming model for disaster relief logistics under uncertainty. OR Spectr. 35 (2013) 905-933.

[7] V. Cantillo, I. Serrano, L.F. Macea and J. Holguín-Veras, Discrete choice approach for assessing deprivation cost in humanitarian relief operations. Soc.-Econ. Planning Sci. 63 (2018) 33-46.

[8] X. Cao, F. Liang, H. Chen and Y. Liu, Circuity characteristics of urban travel based on GPS data: a case study of Guangzhou. Sustainability. 9 (2017) 2156.

[9] C. Cao, C. Li, Q. Yang, Y. Liu and T. Qu, A novel multi-objective programming model of relief distribution for sustainable disaster supply chain in large-scale natural disasters. J. Cleaner Prod. 174 (2018) 1422-1435.

[10] M.H. Dehghani Sadrabadi, R. Ghousi and A. Makui, An enhanced robust possibilistic programming approach for forward distribution network design with the aim of establishing social justice: a real-world application. J. Ind. Syst. Eng. 12 (2019) 76-106.

[11] M.H. Dehghani Sadrabadi, A. Jafari Nodoushan and A. Bozorgi-Amiri, Resilient supply chain under risks: a network and structural perspective. Iran. J. Manage. Stud. 14 (2021) 735-760.

[12] M.H. Dehghani Sadrabadi, R. Ghousi and A. Makui, Designing a disruption-aware supply chain network considering precautionary and contingency strategies: a real-life case study. RAIRO-Oper. Res. 55 (2021) 2827-2860.

[13] R. Dubey and A. Gunasekaran, The sustainable humanitarian supply chain design: agility, adaptability and alignment. Int. J. Logistics Res. App. 19 (2016) 62-82.

[14] R. Espejo and V. Lepskiy, An agenda for ontological cybernetics and social responsibility. Kybernetes (2020). DOI: 10.1108/k06-2020-0390.

[15] T. Furuta and K.-I. Tanaka, Minisum and minimax location models for helicopter emergency medical service systems. J. Oper. Res. Soc. Jpn. 56 (2013) 221-242.

[16] G. Galindo and R. Batta, Review of recent developments in OR/MS research in disaster operations management. Eur. J. Oper. Res. 230 (2013) 201-211.

[17] A. Ghaderi and M. Momeni, A multi-period maximal coverage model for locating simultaneous ground and air emergency medical services facilities. J. Ambient Intell. Humanized Comput. 12 (2021) 1577-1600.

[18] I. Haavisto and G. Kovács, Perspectives on sustainability in humanitarian supply chains. Disaster Prev. Manage. 23 (2014) 610-631.

[19] A. Hasani and H. Mokhtari, An integrated relief network design model under uncertainty: a case of Iran. Safety Sci. 111 (2019) $22-36$.

[20] J. Holguín-Veras, N. Pérez, M. Jaller, L.N. Van Wassenhove and F. Aros-Vera, On the appropriate objective function for post-disaster humanitarian logistics models. J. Oper. Manage. 31 (2013) 262-280. 
[21] H. Kaur and S.P. Singh, Sustainable procurement and logistics for disaster resilient supply chain. Ann. Oper. Res. 283 (2019) 309-354.

[22] O. Kebriyaii, M. Hamzehei and M. Khalilzadeh, A disaster relief commodity supply chain network considering emergency relief volunteers: a case study. To appear in: J. Humanitarian Logistics Supply Chain Manage. (2021). DOI: 10.1108/JHLSCM-082020-0073.

[23] S. Khoshnoodmotlagh, A. Daneshi, S. Gharari, J. Verrelst, M. Mirzaei and H. Omrani, Urban morphology detection and it's linking with land surface temperature: a case study for Tehran Metropolis, Iran. Sustainable Cities Soc. 74 (2021) 103228.

[24] N. Kunz and S. Gold, Sustainable humanitarian supply chain management-exploring new theory. Int. J. Logistics Res. App. 20 (2017) 85-104.

[25] Y. Liu and B. Guo, A lexicographic approach to postdisaster relief logistics planning considering fill rates and costs under uncertainty. Math. Prob. Eng. 2014 (2014) 939853.

[26] J. Liu and K. Xie, Emergency materials transportation model in disasters based on dynamic programming and ant colony optimization. Kybernetes 46 (2017) 656-671.

[27] S. Mansoori, A. Bozorgi-Amiri and M.S. Pishvaee, A robust multi-objective humanitarian relief chain network design for earthquake response, with evacuation assumption under uncertainties. Neural Comput. App. 32 (2020) $2183-2203$.

[28] M. Mousazadeh, S.A. Torabi and M.S. Pishvaee, Green and reverse logistics management under fuzziness. In: Supply Chain Management Under Fuzziness. Springer (2014) 607-637.

[29] M. Nili, S.M. Seyedhosseini, M.S. Jabalameli and E. Dehghani, A multi-objective optimization model to sustainable closed-loop solar photovoltaic supply chain network design: a case study in Iran. Renew. Sustainable Energy Rev. 150 (2021) 111428.

[30] M. Nili, S.M. Seyedhosseini, M.S. Jabalameli and E. Dehghani, An integrated model for designing a bi-objective closed-loop solar photovoltaic supply chain network considering environmental impacts: a case study in Iran. J. Ind. Syst. Eng. 13 (2021) 243-280.

[31] P. Oberhofer, E.E. Blanco and A.J. Craig, Carbon efficiency of humanitarian supply chains: evidence from French Red Cross operations. In:Logistics Management. Springer (2015) 53-66.

[32] M.S. Pishvaee, S.A. Torabi and J. Razmi, Credibility-based fuzzy mathematical programming model for green logistics design under uncertainty. Comput. Ind. Eng. 62 (2012) 624-632.

[33] R. Pradhananga, F. Mutlu, S. Pokharel, J. Holguín-Veras and D. Seth, An integrated resource allocation and distribution model for pre-disaster planning. Comput. Ind. Eng. 91 (2016) 229-238.

[34] M. Rahafrooz and M. Alinaghian, A novel robust chance constrained possibilistic programming model for disaster relief logistics under uncertainty. Int. J. Ind. Eng. Comput. 7 (2016) 649-670.

[35] C.G. Rawls and M.A. Turnquist, Pre-positioning and dynamic delivery planning for short-term response following a natural disaster. Soc.-Econ. Planning Sci. 46 (2012) 46-54.

[36] M. Re, Annual Review: Natural Catastrophes 2004. Knowledge Series (2005).

[37] F. Sabouhi, A. Bozorgi-Amiri, M. Moshref-Javadi and M. Heydari, An integrated routing and scheduling model for evacuation and commodity distribution in large-scale disaster relief operations: a case study. Ann. Oper. Res. 283 (2019) 643-677.

[38] F. Sabouhi, Z.S. Tavakoli, A. Bozorgi-Amiri and J.-B. Sheu, A robust possibilistic programming multi-objective model for locating transfer points and shelters in disaster relief. Transp. A: Transp. Sci. 15 (2019) 326-353.

[39] F. Sabouhi, A. Bozorgi-Amiri and P. Vaez, Stochastic optimization for transportation planning in disaster relief under disruption and uncertainty. Kybernetes 50 (2021) 2632-2650.

[40] F. Sabouhi, M.S. Jabalameli and A. Jabbarzadeh, An optimization approach for sustainable and resilient supply chain design with regional considerations. Comput. Ind. Eng. 159 (2021) 107510.

[41] J. Salmerón and A. Apte, Stochastic optimization for natural disaster asset prepositioning. Prod. Oper. Manage. 19 (2010) $561-574$.

[42] M. Shahriari, A. Bozorgi-Amiri, S. Tavakoli and A. Yousefi-Babadi, Bi-objective approach for placing ground and air ambulance base and helipad locations in order to optimize EMS response. Am. J. Emergency Med. 35 (2017) 1873-1881.

[43] J.-B. Sheu and C. Pan, Relief supply collaboration for emergency logistics responses to large-scale disasters. Transp. A Transp. Sci. 11 (2015) 210-242.

[44] S. Tofighi, S.A. Torabi and S.A. Mansouri, Humanitarian logistics network design under mixed uncertainty. Eur. J. Oper. Res. 250 (2016) 239-250.

[45] G.-H. Tzeng, H.-J. Cheng and T.D. Huang, Multi-objective optimal planning for designing relief delivery systems. Transp. Res. Part E: Logistics Transp. Rev. 43 (2007) 673-686.

[46] R. Ulucak and S.U.-D. Khan, Determinants of the ecological footprint: role of renewable energy, natural resources, and urbanization. Sustainable Cities Soc. 54 (2020) 101996.

[47] P. Vaez, F. Sabouhi and M.S. Jabalameli, Sustainability in a lot-sizing and scheduling problem with delivery time window and sequence-dependent setup cost consideration. Sustainable Cities Soc. 51 (2019) 101718. 
[48] L. Wang, L. Yang, Z. Gao, S. Li and X. Zhou, Evacuation planning for disaster responses: A stochastic programming framework. Transp. Res. Part C: Emerging Technol. 69 (2016) 150-172.

[49] X. Wei, A. Al-Refaie, M. Robles and B. Noche, A sustainable humanitarian relief network study for the Wenchuan earthquake. In: Humanitarian Logistics and Sustainability. Springer (2015) 193-213.

\section{Subscribe to Open (S20) A fair and sustainable open access model}

This journal is currently published in open access under a Subscribe-to-Open model (S2O). S2O is a transformative model that aims to move subscription journals to open access. Open access is the free, immediate, online availability of research articles combined with the rights to use these articles fully in the digital environment. We are thankful to our subscribers and sponsors for making it possible to publish this journal in open access, free of charge for authors.

\section{Please help to maintain this journal in open access!}

Check that your library subscribes to the journal, or make a personal donation to the S2O programme, by contacting subscribers@edpsciences.org

More information, including a list of sponsors and a financial transparency report, available at: https://www. edpsciences.org/en/maths-s2o-programme 